\title{
THE DEVELOPMENT OF A MATERNAL PREGNANCY REACTION IN THE FERRET
}

\author{
F. BEGK \\ Department of Anatomy, University of Leicester, Leicester LE1 7RH
}

(Received 1st October 1973)

\begin{abstract}
Summary. A segment of the uterus in seven ferrets was isolated surgically before mating. The endometrium of this segment was traumatized at laparotomy 12 days after mating. Histological and electron microscopic examination of the traumatized endometrium 8 days later showed the development of a maternal pregnancy reaction. This was identical to the endometrial response resulting from the presence of normal trophoblast at an implantation site. It consisted of the formation and subsequent necrosis of symplasmal nests of endometrial epithelium and hypertrophy of the cells lining the endometrial capillaries. The capillary cells were cubical or columnar in shape and had a welldeveloped rough endoplasmic reticulum and Golgi apparatus, suggesting a secretory function. The cells appeared to produce a thick acid mucopolysaccharide membrane which might normally play a part in embryonic nutrition.

Traumatization of similarly isolated segments of the uterus in ferrets during oestrus and anoestrus resulted in no specific response.
\end{abstract}

\section{INTRODUGTION}

Over 60 years ago, Loeb (1907a, b) observed the uterine response to trauma applied at an optimal time after induction of pseudopregnancy in the guineapig. Although the stimulus applied was non-specific in nature, its effect upon endometrial morphology resembled the changes characteristic of implantation and Loeb introduced the term 'deciduoma' to describe the uterine reaction produced. By definition, the decidua is that part of the endometrium which is shed with the fetal membranes at parturition and a characteristic of normal pregnancy in many haemochorial placental types, such as the guinea-pig, is the conversion of the spindle-shaped cells of the endometrial stroma into large rounded forms containing abundant glycogen and lipid. These are called decidual cells (for review, see Finn, 1971) since they form the greater part of the decidua. The differentiation of decidual cells, though often the most dramatic change seen at implantation, may not be the only one occurring even in many haemochorial forms (Boyd \& Hamilton, 1952; Amoroso, 1952). In species as diverse as the macaque (Wislocki \& Streeter, 1938) and the rabbit (Chipman, 1903), considerable uterine epithelial proliferation is associated with early trophoblastic invasion. On the other hand, the uterine stroma in some endotheliochorial placentae does not differentiate into decidual cells at all 
although maternal tissue is shed at parturition. Artificially induced 'decidualization' (Shelesnyak, 1962) of varying morphology (for review, see De Feo, 1967) has been reported in the rat (Selye \& McKeown, 1935), mouse (Parkes, 1929), hamster (Kent \& Atkins, 1959) and macaque (Hisaw, 1935). These observations make it clear that Loeb was really defining an artificially induced maternal pregnancy reaction (MPR) rather than a particular cellular response to trauma.

There appears to be only one detailed reference to the attempted experimental production of an MPR in carnivores. Krainz (1914) found that cutting the bitch uterus was ineffective during anoestrus and oestrus but produced cystic enlargement of the uterine glands if performed after ovulation at the stage of glandular cell proliferation. The enlarged glands were divisible into a superficial spongy zone separated by a compact cellular layer from the basal parts of the glands which were a little dilated but nevertheless separated by wellformed interglandular connective tissue. Only two animals were found to be in this condition and a detailed microscopic examination of their endometrium is not reported. It is thus impossible to say whether a symplasma was formed or whether decidual cells (which in normal pregnancy develop around the basal parts of the glands in this species) were present.

The effect of endometrial traumatization in the ferret, a mustelid carnivore with endotheliochorial placentation, is now described. In Mustelidae, the normal placenta develops as a result of trophoblastic invasion into large syncytial masses of maternal epithelial cells principally formed from the ducts of the endometrial glands. The connective tissue cells of the endometrial stroma are eventually destroyed by trophoblast and no decidual cells are formed. The endothelial cells of the endometrial capillaries, however, become greatly hypertrophied and encircled by syncytiotrophoblast. A thick acid mucopolysaccharide membrane secreted, at least in part, by the capillary wall separates the maternal and fetal cells. It was of interest to see whether an MPR could be obtained in an animal that does not produce decidual cells and whether, in such an animal, the specific maternal reactions to the presence of a blastocyst (formation of syncytial masses, hypertrophy of the capillary walls and secretion of an acid mucopolysaccharide membrane) could be induced by appropriately applied non-specific stimuli.

\section{MATERIALS AND METHODS}

Eleven ferrets were used. Under intraperitoneal Nembutal anaesthesia, their uteri were sectioned transversely between paired nylon sutures placed at the ovarian and cervical ends of one horn, thus sealing off the lumen of the isolated segment from the remainder of the uterus. Care was taken to ensure that the blood supply to the isolated portion of the uterus was left intact so that the endocrine environment was similar to that of the contralateral horn of the same animal. Seven of the animals were mated at oestrus; the uteri of two had been surgically prepared during anoestrus and the remainder during oestrus. Mating took place between 14.00 and 17.00 hours except for one pair when the animals remained together overnight because coitus had not been observed by the end of the afternoon period. The day of mating was designated Day 0 of 

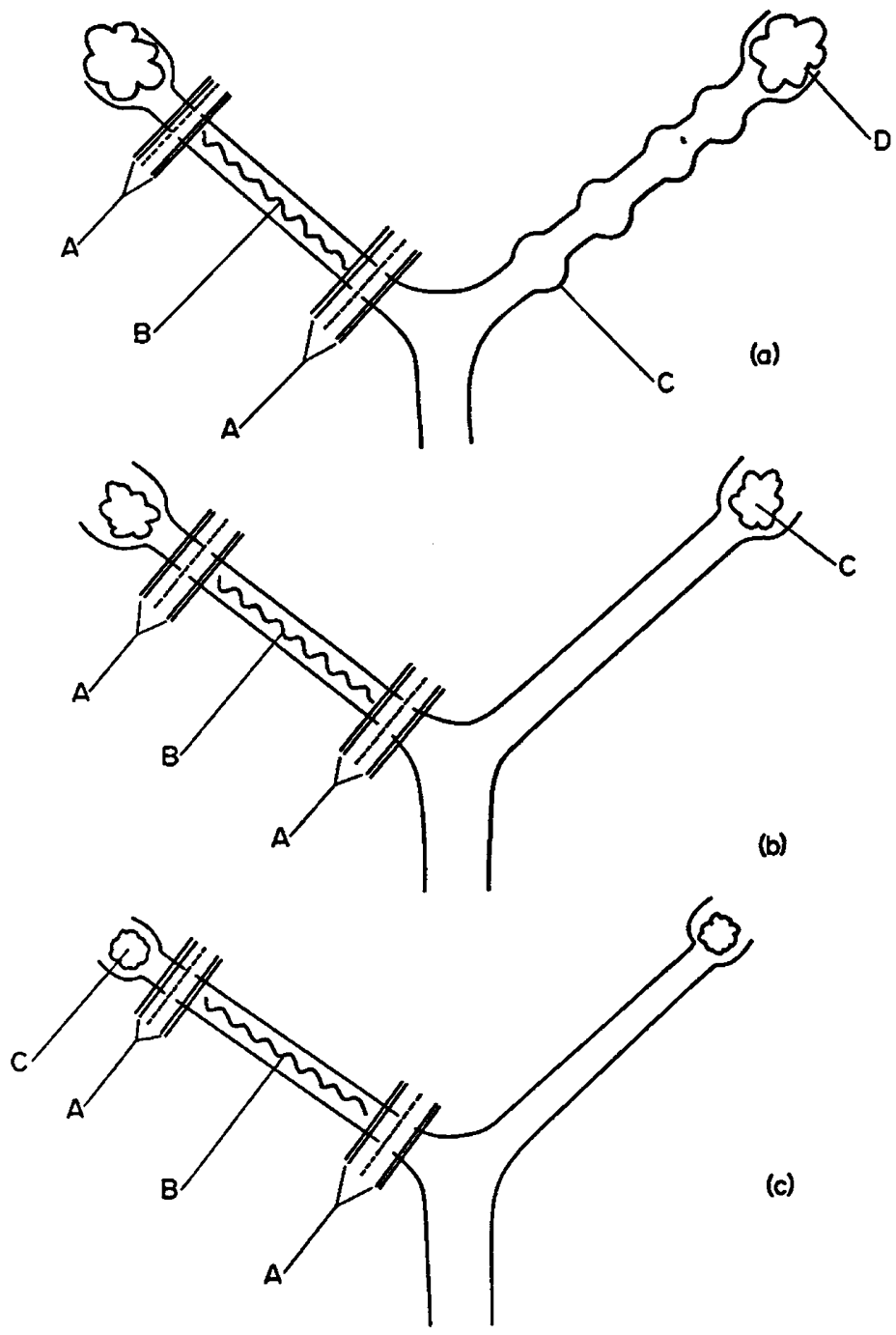

(c)

TexT-FIG. 1. (a) The experimental procedure used with pregnant ferrets. A, Uterus transected between nylon sutures before mating; B, stimulation of endometrium (nylon thread or arachis oil) on the 12th day after mating; C, uterine swellings due to implanted blastocysts seen on the 12th day after mating; $D$, corpora lutea visible on ovarian surface on the 12 th day after mating.

(b) The experimental procedure used with oestrous ferrets. A, Uterus transected between nylon sutures; B, stimulation of the endometrium either by injection of arachis oil at the time of transecting the uterus between nylon sutures or by insertion of a nylon thread 2 weeks later; C, enlarged Graafian follicles seen on the surface of the ovary at oestrus.

(c) The experimental procedure used with anoestrous ferrets. A, Uterus transected between nylon sutures; $B$, stimulation of the endometrium either by injection of arachis oil at the time of transecting the uterus between nylon sutures or by insertion of a nylon thread 2 weeks later; $\mathrm{C}$, small ovary during anoestrus without visible follicles or corpora lutea. 
pregnancy. On Day 12 of pregnancy, the endometrium of two pregnant animals was stimulated by injection of arachis oil into the uterine lumen (together with some trauma from the injecting needle) and that of the remaining five by means of a thick nylon thread placed intraluminally. At the time of endometrial traumatization, the untreated uterine horn was seen to be distended by implanting blastocysts at intervals along its length but such swellings were never seen in the isolated uterine segments (Text-fig. la). The endometrium of the isolated uterine segment was also traumatized in two surgically prepared but unmated animals at oestrus and in two further animals at anoestrus. In both the oestrous (Text-fig. 1b) and the anoestrous ferrets (Text-fig. 1c), arachis oil was injected into the isolated portion of the uterus of one animal at laparotomy, while in the other the isolated segment was threaded with nylon 2 weeks after laparotomy.

All animals were killed 8 days after uterine trauma and sections through the isolated (traumatized) part of the uterine horn were prepared for light and electron microscopic examination. Sections from the extreme proximal and distal (untraumatized) parts of the interrupted horn as well as from the undamaged contralateral horn were also examined.

For light microscopy, sections were fixed in Bouin's fluid, embedded in paraffin wax and then stained with haematoxylin and eosin or with alcian blue at $\mathrm{pH} 2 \cdot 5$, using nuclear fast red as a counterstain. For electron microscopy, tissues were fixed in Karnovsky's (1965) fixative, washed in sodium cacodylate $\mathrm{HCl}$ buffer at $\mathrm{pH} 7.2$ and post-fixed in Caulfield's (1957) osmic acid fixative. Sections were stained in lead citrate and uranyl acetate and examined in an Elmiskop I.

\section{RESULTS}

\section{Macroscopic appearances}

At the time of endometrial traumatization, the isolated segments of the uterine horn in pregnant and in oestrous or anoestrous animals either looked quite normal or were very slightly distended by retained secretions. When pregnant animals were killed 8 days later, the uterine wall in these areas was greatly hypertrophied. By contrast, the contralateral horns had the normal appearance of the ferret uterus at 20 days of pregnancy and the uterus proximal and distal to the isolated segment either contained developing conceptuses (rarely, in the process of resorption) or else its dimensions corresponded to that of the regions between conceptuses in a normal ferret gestation at 20 days. When the anoestrous and oestrous animals were killed, the isolated segment of the uterus was sometimes a little distended because of the contained foreign material but there was no massive hypertrophy of its walls. The remainder of the uterus was normal in appearance.

\section{Histology}

Haematoxylin and eosin-stained sections from isolated traumatized segments of the pregnant ferret uterus showed extensive but apparently discrete areas of symplasma in which darkly staining nuclei were crowded together in a region 
of featureless eosinophilic cytoplasm (Pl. 1, Fig. 1). The symplasmal nests lay below the endometrial surface and were similar, histologically, to symplasmal areas demonstrable at the pregnancy sites in the necks of the uterine glands. The symplasmal masses during normal pregnancy provide a pabulum of histiotroph for invading trophoblast (Pl. 1, Fig. 3) and often show signs of necrosis in their central regions. In many sections, necrosis of the symplasma was complete and scattered nests of cell débris were seen in the endometrium of the traumatized horn and at sites of trophoblastic penetration in the contralateral horn. Examination of the endometrial capillaries at gestation sites in the untreated uterine horns showed considerable hypertrophy of the endothelium in the region of the symplasmal nests and areas of cell necrosis (Pl. 1, Fig. 4). This feature was also present in the isolated traumatized uterine segment (Pl. 2, Fig. 5). The presence of a foreign body in the lumen of the isolated uterine segment had also caused a certain amount of surface necrosis associated with the presence of eosinophilic cell débris in the uterine lumen. This feature was irregular in appearance and not focal in nature. It affected all the constituent cells in the superficial part of the endometrium (including the maternal capillary endothelium) and was absent in the contralateral (non-traumatized) uterine horn. In areas in which there were no implantation sites, the histology of the uterine horn proximal and distal to the isolated traumatized uterine segment was identical to the area between conceptuses in the untreated (contralateral) horn (PI. 2, Fig. 6).

Trauma of the uterine endometrium during anoestrus and oestrus had no histologically visible effect apart from occasional patches of surface necrosis. An atrophic endometrium with low epithelial cells and little evidence of secretion was present in both the treated and untreated uterine horns during anoestrus. During oestrus, the endometrial cells became columnar and the stroma more oedematous but the presence of a foreign body had no specific effect on uterine histology.

Tests for acid mucopolysaccharide showed the presence of a thick alcian blue-positive membrane surrounding the hypertrophied endometrial capillaries of the traumatized horn in the pregnant animals (PI. 2, Fig. 7). More precise histochemical characterization of the membrane was not attempted but it was noted that an identical structure surrounded the hypertrophied maternal capillaries present in areas of trophoblastic penetration in the contralateral horns. Alcian blue staining and thickening of the capillary basement membrane was not seen in the endometrium of anoestrous or oestrous ferrets whether or not a foreign body was present in the uterine lumen.

\section{Electron microscopy}

Electron microscopic observations confirmed and extended those made with the light microscope. Symplasma formation was shown in the isolated traumatized horn from a pregnant animal (Pl. 2, Fig. 8) and the proximity of an hypertrophied endometrial capillary to an area of extensive epithelial necrosis in the same specimen was also shown (Pl. 3, Fig. 9). The cells lining the endometrial capillaries were hypertrophied (PI. 3, Fig. 10) and active endocytosis from the capillary lumen was probably indicated by the presence of small 
vesicles associated with the luminal plasma membrane. There was considerable development of granular endoplasmic reticulum and the perinuclear Golgi apparatus was extensive. Small vesicles of varying electron density were numerous; some of these were apparently endocytic vesicles but sometimes the vesicles were closely associated with the Golgi apparatus and they were frequently seen close to the surface of the cell facing away from the capillary lumen. Occasionally there was continuity between the lining of one of them and the pericapillary space (Pl. 3, Fig. 11). Lipid droplets were occasionally seen in the cellular cytoplasm but dense membrane-bounded bodies suggestive of lysosomal activity were rare. Lying in the pericapillary space, electron-dense material of floccular appearance constituted a thick membrane. The latter often contained small collections of collagen fibres which may have been remnants of the stromal connective tissue. Junctional complexes between the capillary endothelial cells were often placed well down their lateral walls,

\section{EXPLANATION OF PLATES}

PLATE 1

Frg. 1. Isolated horn of a ferret uterus which was traumatized 12 days after copulation and removed 8 days later. Areas of symplasma (S) are clearly seen in the endometrium and hypertrophied maternal capillaries can be identified more superficially (arrows). $\times 140$.

FIg. 2. Symplasma (S) from a normal placental site in the contralateral horn of the uterus shown in Fig. 1. $\times 180$.

Fig. 3. Remains of symplasmal cell nest surrounded by syncytiotrophoblast (Syn). The arrows indicate hypertrophied maternal capillaries. Gytotrophoblast (C), fetal mesenchyme $(M)$. Normal placenta at 20 days of gestation. $\times 450$.

Frg. 4. Hypertrophied maternal capillaries in the normal ferret placenta at 20 days of gestation. $\times 190$.

\section{PLATE 2}

Frg. 5. Hypertrophied capillaries from the isolated contralateral horn of the ferret uterus shown in Fig. 4. $\times 160$.

Fig. 6. Section of pregnant ferret uterus distal to the isolated traumatized horn but not in the region of a conceptus. The hypertrophied epithelial cells are thrown into foIds and show no evidence of symplasma formation. There is scanty development of the stroma and no hypertrophy of the maternal capillaries. $\times 175$.

FIG. 7. Acid mucopolysaccharide membrane surrounding the hypertrophied capillaries from traumatized uterine horn shown in Fig. 5. Alcian blue stain, $\mathrm{pH} 2 \cdot 5 . \times 300$.

Frg. 8. Symplasma in the isolated horn of a pregnant ferret uterus which was traumatized 12 days after mating and removed 8 days later. Though plasma and nuclear membranes are in the process of disruption, many subcellular organelles are still remarkably well preserved. $\times 6000$.

\section{PLATE 3}

Fig. 9. Another region of the endometrium from the specimen shown in Fig. 8. The contrast between the symplasma in the lower portion of the picture and the well-preserved hypertrophied endometrial capillary at the top is very clear. The latter is surrounded by a thick membrane (arrows). $\times 3500$.

Fig. 10. Detail of hypertrophied cells lining endometrial capillaries in the isolated traumatized endometrium of a pregnant ferret. Dilated cisternae of granular endoplasmic reticulum are clearly seen and the Golgi apparatus is well developed. The membrane surrounding the capillary consists of flocculent material (arrows) associated with collagen fibres. The latter are probably originally of stromal origin. $\times 6000$.

Fig. 11. Apparent secretion of membrane material from an hypertrophied capillary endothelial cell (at arrow). The nucleus $(\mathrm{N})$ is shown in the region of two nuclear pores. $\times 60,000$. 

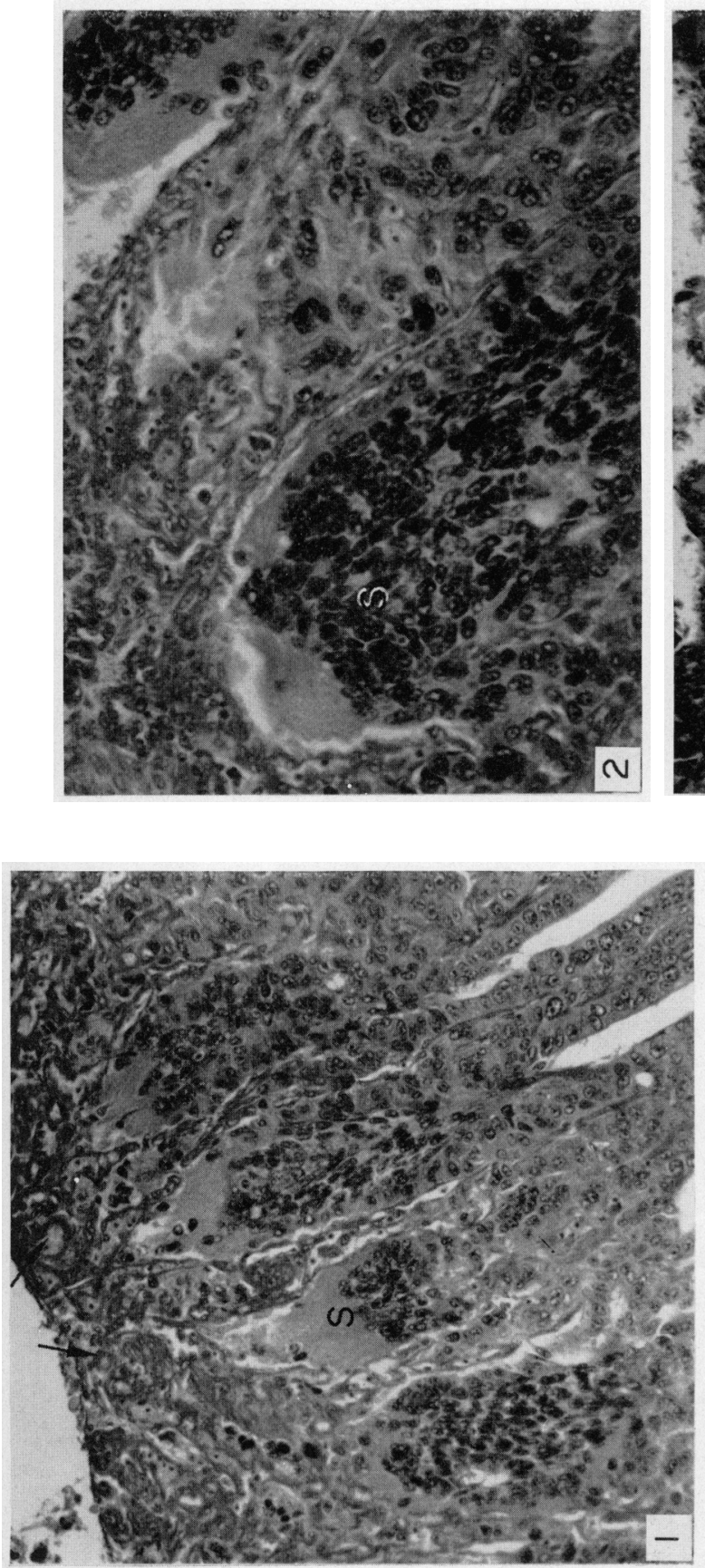
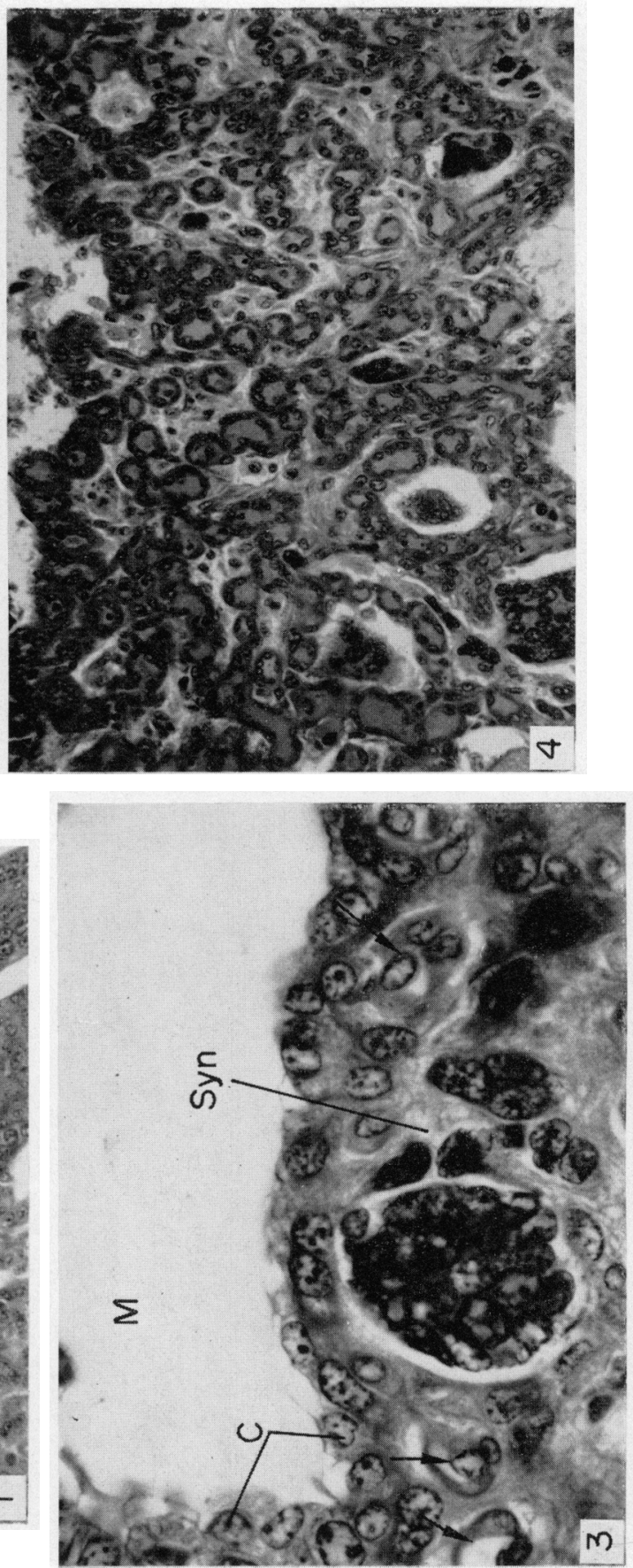

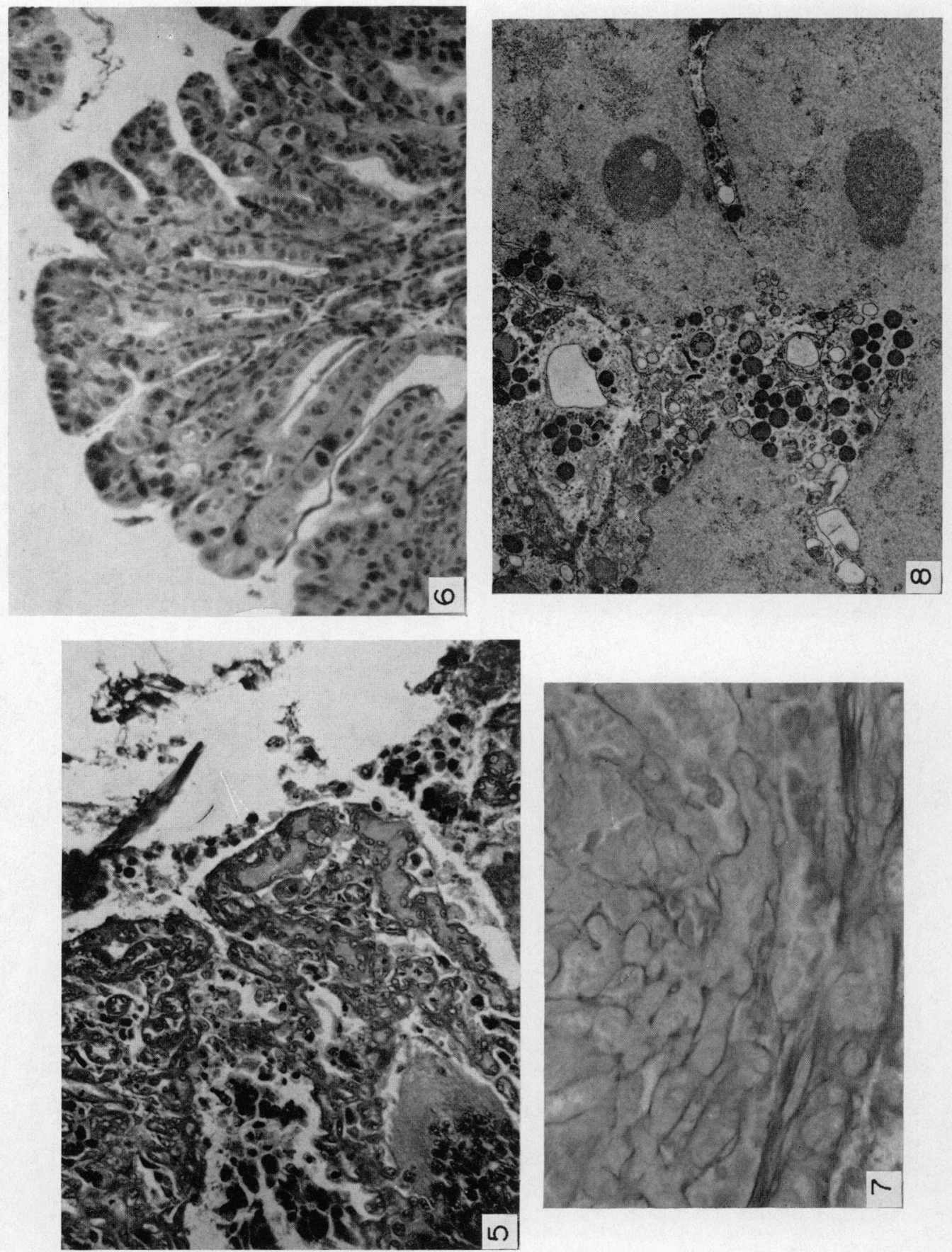
PLAT:3
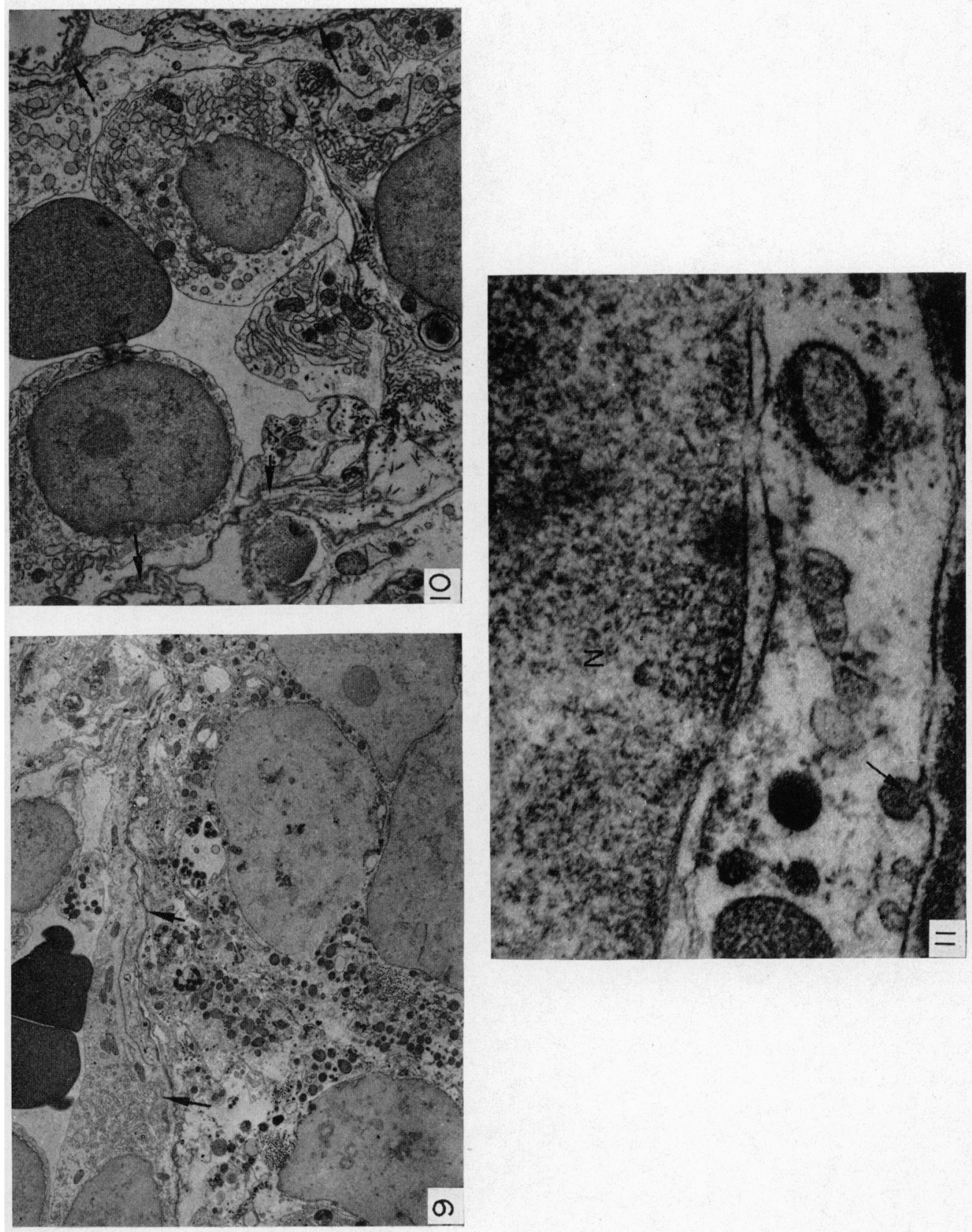
suggesting that they were relatively fixed areas and that cellular hypertrophy had, at least to some extent, involved the luminal portions of the cells.

The electron microscopic appearances seen in the isolated traumatized horns from the pregnant animals were similar in nature to those seen in the maternal tissues of the normal 20-day pregnant contralateral horns. The only difference was that in the latter syncytiotrophoblast had invaded and apparently removed much of the necrotic débris resulting from degeneration of the maternal symplasma.

\section{DISCUSSION}

In describing deciduoma formation in the mouse, Finn (1971) has demonstrated that apart from decidualization of the cells of the endometrial stroma after injection of arachis oil into the uterine lumen of receptive animals, a definite 'implantation cavity' is formed antimesometrially. The deciduomal reaction would appear, therefore, to be not merely a cellular response to nonspecific trauma but rather a topographically orientated MPR. Finn (1971) states that, 'the decidua is not a homogeneous structure but rather a differentiated organ containing a chamber in the centre... Formation of the organ appears to be an inherent function of the sensitised and stimulated uterus'.

Viewed in this light, it is not surprising that a comparable MPR takes place in the ferret even though no decidual cells are formed either as a part of this reaction or in normal pregnancy in this species. Rossman (1940) noted that the reaction of the macaque uterus to stimulation 7 to 12 days after ovulation and treatment with progesterone initially produced an epithelial response similar to that normally occurring in early pregnancy. 'Decidual' cells forming a thick stratum compactum are only described 12 days after traumatization.

Normal placentation in the ferret does not involve trophoblastic penetration and endometrial necrosis in the so-called 'mesometrial gutter'. Furthermore, an antimesometrially placed haematoma develops at 19 days between the trophoblast and the endometrium by rupture of some maternal blood vessels (Strahl \& Ballman, 1915). It would be of interest to see whether similar regional responses could be obtained by applying an even stimulus over the whole of the uterine circumference. Such a stimulus might be achieved by injection of small quantities of arachis oil into the uterus at low pressure with minimal endometrial trauma by the puncturing needle. At present, however, the question of regional specialization of the endometrium must remain an open one.

It has been shown that the histology of the MPR is in all respects similar to that of the normal endometrial reaction in the placental region. The response is not a non-specific counteraction to trauma because the symplasmal regions and necrotic cell nests are often not superficial in position. In this, they resemble their counterpart during normal pregnancy when the formation of symplasmal masses results from proliferation of cells in the necks of the endometrial glands and is not confined to their orifices (Strahl \& Ballman, 1915; Gulamhusein \& Beck, 1973). In addition, the close proximity of necrotic endometrial cells to viable hypertrophied maternal capillaries and the transformation undergone by the capillary endothelium itself makes the reaction quite unlike a generalized 
response to trauma. A superficial reaction to the intrauterine presence of a thread did in fact occur not only in the pregnant animals but also in anoestrous and oestrous ones; this consisted of indiscriminate destruction of superficial tissue involving not only epithelium and connective tissue but also the maternal capillaries together with the accumulation of a certain amount of eosinophilic intrauterine cell débris.

The presence of a thickened alcianophilic membrane surrounding the maternal capillaries in the region of the MPR indicates that at least a substantial part of this membrane is secreted by the maternal capillary cells during normal pregnancy. The transformation of the endothelial cells of these vessels has made them well suited for this purpose. Their hypertrophy is accompanied by the abundant presence of granular endoplasmic reticulum which is moderately distended with secretory material. Well-marked Golgi regions are often seen and numerous vacuoles of varying electron density appear to be associated with these organelles. Some of these vacuoles are probably secretory granules; often, they contain material similar in appearance to the floccular extracellular membrane and occasionally they are continuous with the basal plasma membrane of the cell. It is tempting to conceive of these appearances as indicative of active cellular secretion followed by exocytosis.

Little attention has been paid to the functional nature of the thickened membrane surrounding the maternal capillaries in the mustelid placenta. In view of the above observations, the membrane may be in a state of constant turnover. In the normal placenta, there is morphological evidence of endocytosis of membrane material by surrounding syncytiotrophoblast (F. Beck \& A. P. Gulamhusein, in preparation), and the 'membrane' may therefore be an active secretion elaborated by the maternal capillaries for embryonic nutrition.

In the present experiment, necrosis of the symplasma appears to take place at about the same rate in the experimental and control horns of pregnant animals. This suggests that in normal pregnancy the necrotic process precedes ingestion by trophoblast and provides circumstantial evidence against the secretion of cytolytic material by the latter. Indeed, it is difficult to see how such secretion could take place in view of the integrity and hypertrophy of the endometrial capillaries.

Marston \& Kelly (1969) have studied the contraceptive action of intrauterine devices in the ferret. They put a silk suture into the uterine lumen in late anoestrus or early pro-oestrus, and mated their animals 2 or more weeks later (when they were in oestrus). Histological observations were made 7, 10 and 14 days after mating but nothing resembling an MPR was found. The only constant lesions were superficial endometrial erosion and some leucocytic infiltration in the immediate vicinity of the device.

Although these experiments are not strictly comparable with the ones reported here, the results are interesting when taken in conjunction with the present observation that no MPR could be obtained by traumatization of the uterus in anoestrous or oestrous animals. Apparently, the presence of an intrauterine device in situ does not stimulate the development of an MPR during the preimplantation period. The fact that Marston \& Kelly (1969) did not 
see an MPR in 14-day pregnant animals may be because there had been no time for it to develop significantly since the critical day of implantation (Day 12). Other interpretations (such as inhibition of the MPR - similar to that found by De Feo (1963) in the rat-following the presence of an intrauterine foreign body before implantation) are also possible.

\section{ACKNOWLEDGMENTS}

I am grateful to Dr J. Horn who carried out many of the operative procedures described and has shown great interest in this work. I am also indebted to the Wellcome Trust for a grant in aid of research.

\section{REFERENCES}

Amoroso, E. C. (1952) Placentation. In Marshall's Physiology of Reproduction, 3rd edn, Vol. II, pp. 127311. Ed. A. S. Parkes. Longmans Green, London.

Boyd, J. D. \& Hamilton, W. J. (1952) Cleavage, early development and implantation of the egg. In Marshall's Physiology of Reproduction, 3rd edn, Vol. II, pp. 1-126. Ed. A. S. Parkes. Longmans Green, London.

CAULfiELd, J. B. (1957) Effects of varying the vehicle for $\mathrm{OsO}_{4}$ in tissue fixation. 7. biophys. biochem. Cytol. 3, 827.

Chipman, W. (1903) Observations on the placenta of the rabbit with special reference to the presence of glycogen, fat and iron. Rep. Lab. R. Coll. Physns Edinb. 8, 227.

DE Fro, V.J. (1963) Determination of the sensitive period for the induction of deciduomata in the rat by different inducing procedures. Endocrinology, 73, 488.

DE FEo, V. J. (1967) Decidualization. In Cellular Biology of the Uterus, pp. 191-290. Ed. R. M. Wynn. Appleton-Century-Crofts, New York.

Finn, G. A. (1971) The biology of decidual cells. Adv. Reprod. Physiol. 5, 1.

Gulamhusein, A. P. \& Beck, F. (1973) Light and electron microscopic observations at the pre- and early post-implantation stages in the ferret uterus. F. Anat. 115, 159.

Hisaw, F. L. (1935) The physiology of menstruation in macacus rhesus monkeys. I. Influence of the follicular and corpus luteum hormones. II. Effects of anterior pituitary extracts. Am. F. Obstet. Gynec. 29, 638.

KARNOVSKY, M. J. (1965) A formaldehyde-glutaraldehyde fixative of high osmolarity for use in electron microscopy. 7. Cell Biol. 27, 137A.

KeNT, G. C., JR \& ATKINs, G. (1959) Duration of pseudopregnancy in normal and uterine-traumatised hamsters. Proc. Soc. exp. Biol. Med. 101, 106.

KraInz, K. (1914) Über Reizwirkungen von Fremdkörpern auf die Uterusschleimhaut der Hündin. Arch. mikrosk. Anat. EntwMech. 84, 122.

LoEB, L. (1907a) Uber die experimentelle Erzeugung von Knoten von Deciduagewebe in dem Uterus des Meerschweinchens nach stattgefundener Copulation. Zentbl. allg. Path. path. Anat. 18, 563.

Lozb, L. (1907b) Wounds of the pregnant uterus. Proc. Soc. exp. Biol. Med. 4, 93.

Marston, J. H. \& Kelly, W. A. (1969) Contraceptive action of intra-uterine devices in the ferret. 7. Reprod. Fert. 18, 419.

PARkes, A. S. (1929) The functions of the corpus luteum. II. The experimental production of placentomata in the mouse. Proc. R. Soc. B, 104, 183.

Rossman, I. (1940) The decidual reaction in the Rhesus monkey (Macaca mulatta). 1. The epithelial proliferation. Am. J. Anat. 66, 277.

Selye, H. \& McKeown, T. (1935) Studies on the physiology of the maternal placenta of the rat. Proc. R. Soc. B, 119, 1 .

Shelesnyak, M. (1962) Decidualisation: the decidua and deciduoma. Perspect. Biol. Med. 5, 503.

Strahl, H. \& Ballman, E. (1915) Embryonalhüllen und Plazenta von Putorius Furo. Abh. preuss. Acad. Wiss. 4, 1.

WrsLockI, G. B. \& STREeTER, G. L. (1938) On the placentation of the macaque (Macaca mulatta) from the time of implantation until the formation of the definitive placenta. Contr. Embryol. 27, 1. 